\begin{tabular}{|c|c|}
\hline Title & $\begin{array}{l}\text { Rhodium(I)-Catalyzed Enantioselective Cyclization of Enynes by Intramolecular Cleavage of the Rh-C Bond by a } \\
\text { Tethered Hydroxy Group }\end{array}$ \\
\hline Author(s) & Oonishi, Y oshihiro; Masusaki, Shuichi; Sakamoto, Shunki; Sato, Y oshihiro \\
\hline Citation & $\begin{array}{l}\text { A ngewandte chemie international edition, 58(26), 8736-8739 } \\
\text { https://doi.org/10.1002/anie.201902832 }\end{array}$ \\
\hline Issue Date & 2019-06-24 \\
\hline Doc URL & http:/hdl.handle.net/2115/78679 \\
\hline Rights & $\begin{array}{l}\text { This is the peer reviewed version of the following article: A ngewandte chemie international edition,58(26),8736- } \\
8739,(2019), \text { which has been published in final form at https://doi.org/10.1002/anie.201902832. This article may be } \\
\text { used for non-commercial purposes in accordance with Wiley Terms and Conditions for U se of Self-A rchived V ersions. }\end{array}$ \\
\hline Type & article (author version) \\
\hline File Information & WoS_90159_Oonishi.pdf \\
\hline
\end{tabular}

Instructions for use 


\title{
Rhodium(I)-Catalyzed Enantioselective Cyclization of Enynes via Intramolecular Cleavage of the Rh-C Bond by a Tethered Hydroxy Group
}

\author{
Yoshihiro Oonishi, ${ }^{*}$ Shuichi Masusaki, Shunki Sakamoto, and Yoshihiro Sato*
}

\begin{abstract}
Rhodium(I)-catalyzed enantioselective intramolecular cyclization of enynes having a hydroxy group in the tether was investigated, and various cyclic compounds possessing a chiral quaternary carbon center were obtained in high yields with high ees. In this cyclization, an $\mathrm{Rh}-\mathrm{C}\left(\mathrm{sp}^{2}\right)$ bond in the rhodacyclopentene intermediate, which was formed via enantioselective oxidative cycloaddition of enynes to a chiral rhodium(I) complex, was intramolecularly cleaved by $\sigma$-bond metathesis of a tethered $\mathrm{O}-\mathrm{H}$ bond in the substrate. Furthermore, it was found that the cyclic compounds were obtained with high ees even when the starting materials having a racemic secondary alcohol moiety were used in this reaction.
\end{abstract}

Transition metal-catalyzed enantioselective cyclization of enynes bearing a 1,1-disubstituted alkene has emerged as an attractive strategy for efficient construction of various carbo- and heterocyclic compounds possessing a chiral quaternary carbon center (Scheme 1). ${ }^{[1]}$ It is well known that these reactions proceed through metallacyclopentene $\mathbf{A}$, which is formed by enantioselective oxidative cycloaddition of alkyne and alkene of enynes to a chiral transition metal complex $\left(M-L_{n}{ }^{*}\right)$. Although intermolecular cyclization between a metallacyclopentene intermediate and other reactants (e.g., Pauson-Khand reaction, [2 $+2+2$ ] cycloaddition, etc.) has been investigated in detail, ${ }^{[2]}$ intramolecular variants remain rare. ${ }^{[3-5]}$ Shibata and coworker reported rhodium(I)-catalyzed intramolecular cyclization of enyne, having an additional alkene in the tether (eq. 1). ${ }^{[3 a, 3 b]}$ Tanaka and coworkers also reported two types of enantioselective intramolecular cyclizations: one is rhodium(I)-catalyzed [2+2+2] cycloaddition of enynes with a tethered carbonyl group ${ }^{[4]}$ and the other is rhodium(I)-catalyzed cyclization of enynes through $\mathrm{sp}^{3} \mathrm{C}$ $\mathrm{H}$ bond activation. ${ }^{[5]}$ We herein report rhodium(I)-catalyzed enantioselective intramolecular cyclization of enyne, ${ }^{[6]}$ having a hydroxy group in the tether, to afford a cyclic compound possessing a chiral quaternary carbon center (eq. 2).

Initially, the cyclization of substrate $\mathbf{1 a}$ using various rhodium(I) complexes was examined (Table 1). The use of achiral bindentate phosphines such as dppe and dppp did not afford the cyclic compound $\mathbf{2 a}$, and the starting material $\mathbf{1 a}$ was recovered (entries 1 and 2). The cyclization of $\mathbf{1 a}$ with $\mathrm{Rh}^{+} / \mathrm{BIPHEP}$ proceeded smoothly, giving the cyclic compound $\mathbf{2 a}$ in good yield (entry 3). ${ }^{[7]}$ Encouraged by this result, we further investigated the use of various chiral ligands in this cyclization, with focus on BINAP-type ligands having a biaryl structure like BIPHEP (entries 4-7). Among the ligands, $(R)-\mathrm{H}_{8}$-BINAP was the most effective ligand in this cyclization, giving $2 a$ in $79 \%$ yield with $86 \%$ ee (entry

[*] Y. Oonishi, S. Masusaki, S. Sakamoto, and Y. Sato Faculty of Pharmaceutical Sciences, Hokkaido University Nishi 6, Kita 12, Kita-kuispisapporo 060-0812 (Japan) sisp? Fax: (+81)11-706-3722

E-mail: oonishi@pharm.hokudai.ac.jp, biyo@pharm.hokudai.ac.jp.

Supporting information for this article is given via a link at the end of the document.
7). It was also found that the cyclization proceeded even at $40^{\circ} \mathrm{C}$ without greatly decreasing the yield and the ee by using $(R)-\mathrm{H}_{8^{-}}$ BINAP as a ligand (entry 8). Next, the influence of a counter anion on this reaction was examined (entries 9-11). It was found that the use of $\mathrm{BAr}^{\mathrm{F}}$ anion shortened the reaction time and improved the enantioselectivity, giving $2 a$ in $73 \%$ yield and $94 \%$ ee (entry 11). ${ }^{[8]}$

Scheme 1. Transition metal-catalyzed enantioselective cyclization of enyne, having a 1,1-disubstituted alkene.

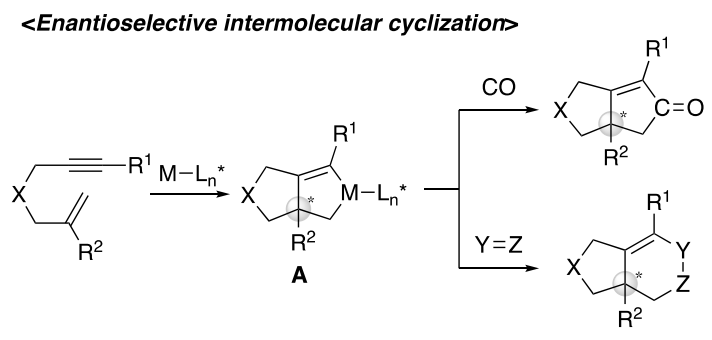

$<$ Enantioselective intramolecular cyclization>

Shibata $(2006,2008)$
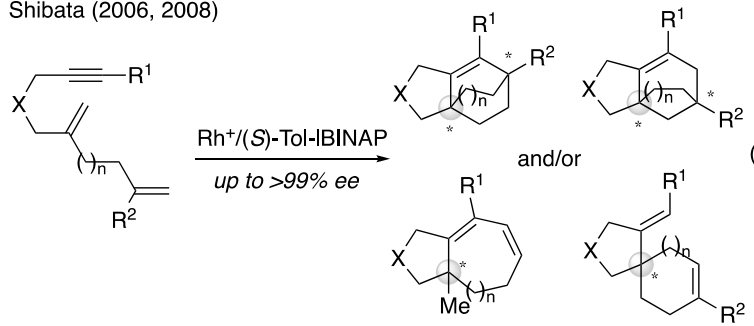

(eq. 1)

This work
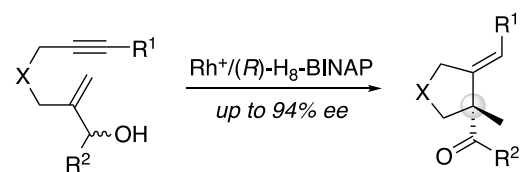

(eq. 2)

Table 1. Cyclization of enyne $1 \mathrm{a}$ under various conditions. ${ }^{[a]}$

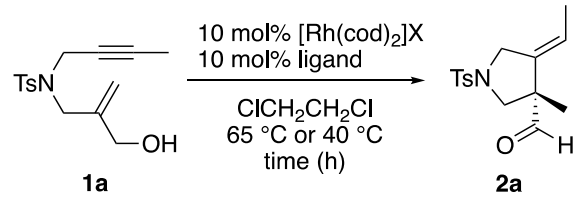

\begin{tabular}{cccccc}
\hline Entry & Ligand & Anion $(\mathrm{X})$ & Time $(\mathrm{h})$ & Yield (\%) & Ee (\%) \\
\hline $1^{[\mathrm{b}]}$ & $\mathrm{dppe}$ & $\mathrm{BF}_{4}$ & 14 & - & - \\
$2^{[\mathrm{b}]}$ & $\mathrm{dppp}$ & $\mathrm{BF}_{4}$ & 22 & - & - \\
3 & BIPHEP & $\mathrm{BF}_{4}$ & 3 & 70 & - \\
4 & $(R)$-BINAP & $\mathrm{BF}_{4}$ & 21 & 78 & 85 \\
5 & $(R)$-Tol-BINAP & $\mathrm{BF}_{4}$ & 3 & 70 & 85 \\
6 & $(R)$-Xyl-BINAP & $\mathrm{BF}_{4}$ & 20 & 76 & 84 \\
7 & $(R)$-H8-BINAP & $\mathrm{BF}_{4}$ & 4 & 79 & 86
\end{tabular}




$\begin{array}{cccccc}8 & (R)-\mathrm{H}_{8}-\mathrm{BINAP} & \mathrm{BF}_{4} & 20 & 78 & 89 \\ 9 & (R)-\mathrm{H}_{8}-\mathrm{BINAP} & \mathrm{ClO}_{4} & 24 & 63 & 85 \\ 10 & (R)-\mathrm{H}_{8}-\mathrm{BINAP} & \mathrm{SbF}_{6} & 18 & 71 & 92 \\ 11 & (R)-\mathrm{H}_{8}-\mathrm{BINAP} & \mathrm{BAr}^{\mathrm{F}} & 7 & 73 & 94\end{array}$

[a] $\left[\mathrm{Rh}(\mathrm{cod})_{2}\right] \times(0.016 \mathrm{mmol})$, ligand $(0.016 \mathrm{mmol}), \mathbf{1 a}(0.016 \mathrm{mmol})$, and $\mathrm{ClCH}_{2} \mathrm{CH}_{2} \mathrm{Cl}(1.6 \mathrm{~mL})$ were employed. The reaction was carried out at $65^{\circ} \mathrm{C}$ (entries 1-7) and at $40{ }^{\circ} \mathrm{C}$ (entries 8-11). [b] 1a was recovered in $100 \%$ yield (entry 1 ) and in $90 \%$ yield (entry 2 ).

With the optimal conditions in hand, the scope and limitations of this cyclization were tested (Table 2 ). The cyclization of $\mathbf{1} \mathbf{b}$ and 1c, having an ethyl or MOM group on the alkyne moiety, proceeded smoothly, giving the desired cyclic compounds $\mathbf{2 b}$ and $\mathbf{2 c}$ in good yields with high ees. When $\mathbf{1 d}$, having an electronwithdrawing group on the alkyne moiety, was employed in this reaction, $\mathbf{2 d}$ was obtained in $77 \%$ yield, albeit with low ee. The cyclization of $\mathbf{1 e - 1 g}$, bearing an aromatic ring on the alkyne moiety, afforded the cyclic compounds $\mathbf{2 e - 2} \mathbf{g}$ in good yields with good ees. ${ }^{[9]}$ This cyclization is applicable for the construction of a carbocyclic ring, in which case, however, the ees of products $\mathbf{2 h}$ and $\mathbf{2 i}$ are moderate ${ }^{[9,10]}$ Interestingly, the reactions of substrates $\mathbf{1 j}-1 \mathbf{l}$, having a racemic secondary alcohol moiety, also proceeded giving the corresponding cyclic compounds $2 \mathbf{j}-2 \mathbf{2}$ in high yields with moderate to high ees. On the other hand, the cyclization of 1,7 - enyne $1 \mathrm{~m}$ did not afford the desired product $\mathbf{2 m}$, but the complex mixtures (an unidentified product as a major product along with various by - products) were produced. In the reaction of 1,8 - enyne $\mathbf{1 n}$, the aldehyde $\mathbf{3 n}$ was obtained in $78 \%$ yield through isomerization of allylic alcohol moiety, probably owing to the difficulty of formation of the seven - membered ring of $\mathbf{2 n}$. When the cyclization of 10, having an oxygen atom in the tether, was carried out, the desired product 20 was not obtained, resulting in complex mixtures.

Table 2. Rhodium(I)-catalyzed cyclization of various enynes 1.

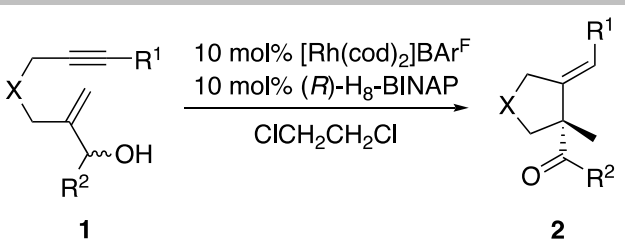<smiles>CC/C=C1\CN([Te])C[C@@]1(C)C=O</smiles>

2b: $65 \%, 94 \%$ ee $(\mathrm{rt}, 20 \mathrm{~h})$

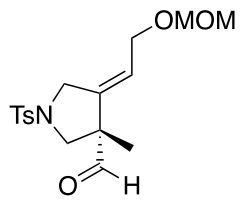

2c: $67 \%, 87 \%$ ee

$\left(40{ }^{\circ} \mathrm{C}, 19 \mathrm{~h}\right)$

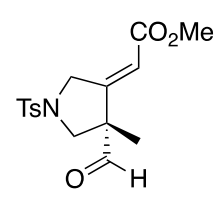

2d: $77 \%, 40 \%$ ee $\left(40{ }^{\circ} \mathrm{C}, 16 \mathrm{~h}\right)$

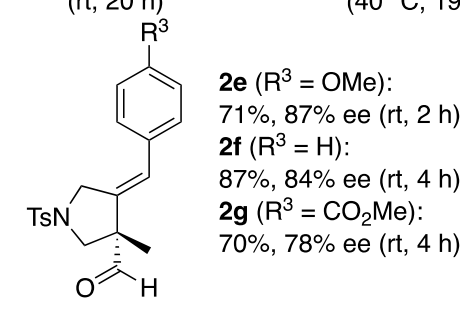

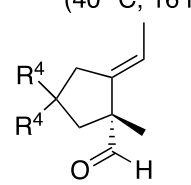

2h $\left(\mathrm{R}^{4}=\mathrm{CO}_{2} \mathrm{Me}\right)$ : $87 \%, 68 \%$ ee (rt, $4 \mathrm{~h}$ ) 2i $\left(\mathrm{R}^{4}=\mathrm{CO}_{2}{ }^{t} \mathrm{Bu}\right)$ : $61 \%, 57 \%$ ee $(\mathrm{rt}, 3 \mathrm{~h})$<smiles>C/C=C1/CN([AlH2])C[C@]1(C)C(C)=O</smiles><smiles>C/C=C1\CN([Al-])C[C@]1(C)C(=O)CCCC</smiles><smiles>C/C=C1\CN([Al])C[C@@]1(C)C(=O)c1ccccc1</smiles>

2j: $93 \%$ yield, $82 \%$ ee 2 k: $82 \%$ yield, $83 \%$ ee $2 \mathbf{2 l}: 75 \%$ yield, $63 \%$ ee $\left(40^{\circ} \mathrm{C}, 4.5 \mathrm{~h}\right)$ $\left(40^{\circ} \mathrm{C}, 6 \mathrm{~h}\right)$

$\left(40^{\circ} \mathrm{C}, 21 \mathrm{~h}\right)$

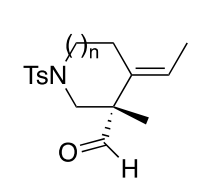

$2 m(n=1): 0 \%(r t, 1 h)$ $2 m(n=1): 0 \%(r t, 1 h)$
$2 n(n=1): 0 \%\left(40^{\circ} \mathrm{C}, 1 h\right)$

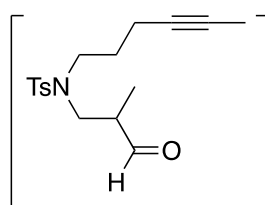

3n: $78 \%$<smiles>C/C=C1/COC[C@]1(C)C=O</smiles>
2o: $0 \%\left(40{ }^{\circ} \mathrm{C}, 24 \mathrm{~h}\right)$

A possible mechanism of this cyclization is depicted in Scheme 2. Initially, enantioselective oxidative cyclization of alkyne and alkene of the substrate 1 to the chiral $\mathrm{Rh}^{+} /(R)-\mathrm{H}_{8}-$ BINAP complex occurs to form the rhodacycle intermediate $\mathbf{i}$, which would contain a chiral carbons center at the ring-junction. ${ }^{[11]}$ Coordination of an oxygen atom of the hydroxy group to the cationic rhodium(III) center (i.e., the intermediate ii) would trigger cleavage of the $\mathrm{Rh}-\mathrm{C}\left(\mathrm{sp}^{2}\right)$ bond via $\sigma$-bond metathesis between the $\mathrm{Rh}-\mathrm{C}\left(\mathrm{sp}^{2}\right)$ bond and $\mathrm{O}-\mathrm{H}$, giving rhodacycle intermediate iii. Subsequently, $\beta$-hydride elimination from iii followed by reductive elimination from iv takes place to afford the cyclic compound 2 having a chiral quaternary carbon center.

Scheme 2. Possible reaction mechanism for the formation of 2 . 


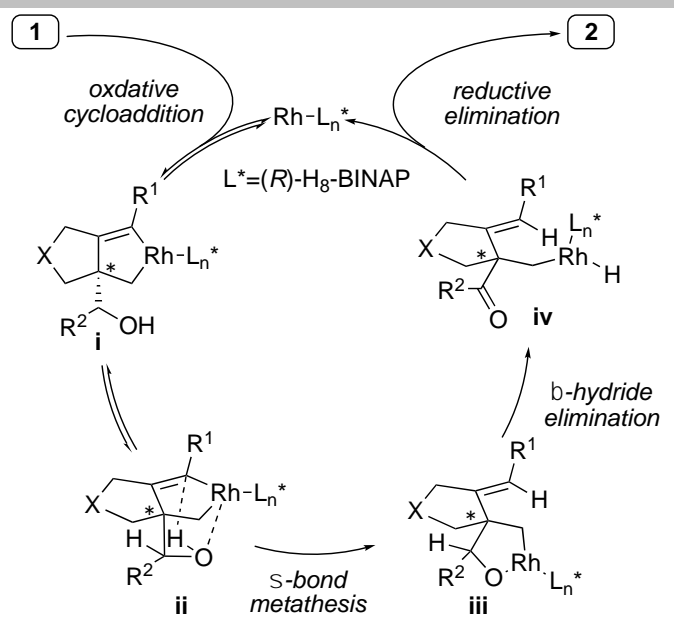

In order to gain mechanistic insights, additional experiments were performed (Scheme 3). First, the deuterated substrate 1j-D was subjected to the above-mentioned optimal reaction conditions. As a result, the corresponding product $2 \mathbf{2}-\mathbf{D}$, having a deuterium at the methyl group, was produced in high yield and high ee with a high D-content (eq. 3), being consistent with the mechanism (especially at the stage from intermediate ii to iv) shown in Scheme 2. Second, a crossover experiment using 1j-D and $\mathbf{1 k}$ was carried out, and $\mathbf{2} \mathbf{j}-\mathbf{D}$ with a high D-content and $\mathbf{2 k}$ without incorporation of deuterium were obtained in reasonable yields and ees. These results indicate that the sequence reactions in the catalytic cycle (i.e., cleavage of the $\mathrm{Rh}-\mathrm{C}\left(\mathrm{sp}^{2}\right)$ bond via $\sigma$-bond metathesis to form intermediate iii from ii, $\beta$ hydride elimination from iii, and reductive elimination from iv) proceed entirely in an intramolecular process (eq. 4). ${ }^{[12]}$

Scheme 3. Mechanistic studies.

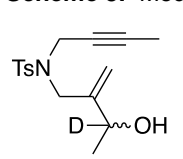

$10 \mathrm{~mol} \%\left[\mathrm{Rh}(\mathrm{cod})_{2}\right] \mathrm{BAr} F$
$10 \mathrm{~mol} \%(R)-\mathrm{H}_{8}-\mathrm{BINAP}$
$\underset{\mathrm{ClCH}}{\mathrm{CH}_{2} \mathrm{CH}_{2} \mathrm{Cl}}$
$40{ }^{\circ} \mathrm{C}, 8 \mathrm{~h}$

$1 j-D$

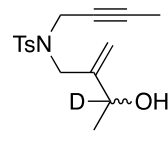

1j-D

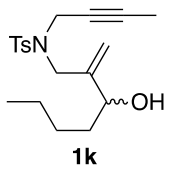

$10 \mathrm{~mol} \%\left[\mathrm{Rh}(\mathrm{cod})_{2}\right] \mathrm{BAr} \mathrm{F}^{\mathrm{F}}$ $10 \mathrm{~mol} \%(R)-\mathrm{H}_{8}$-BINAP $\quad$ 2j-D: $74 \%$ yield, $83 \%$ ee (D-content $>95 \%$ ) $40^{\circ} \mathrm{C}, 6 \mathrm{~h}$

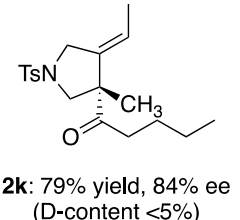

As mentioned above, the products $2 \mathbf{j}-2$ I were produced in high ee even though the racemic starting materials $1 \mathbf{j}$-1I were used in this cyclization (Table 1). Thus, we checked the effect of the absolute configuration of substrates $1 \mathbf{j}-1 /$ on the reactivity and enantioselectivity of the cyclization (Scheme 4). When the reaction of optically pure $\left(>99 \%\right.$ ee) $(S)-1 \mathbf{j}$ using $(R)-\mathrm{H}_{8}$-BINAP was carried out, the product $(S)-2 \mathbf{j}$ was obtained in $82 \%$ yield with $92 \%$ ee, results that are the comparable to results of the reaction of racemic $1 \mathrm{j}$ shown in Table 2. On the other hand, the cyclization of $(S)$-1j using $(S)-\mathrm{H}_{8}$-BINAP afforded the cyclic compound $(R)-2$ j in $83 \%$ yield with $68 \%$ ee. These results suggest that the absolute configuration of the product $\mathbf{2} \mathbf{j}$ is basically controlled by the chirality of the ligand. Furthermore, the decrease of the product's ee when the combination of an $(S)$-substrate and an $(S)$-ligand was used also suggests that this combination and vice versa (i.e., the combination of an $(R)$-substrate and an $(R)$-ligand) would be a mismatched pair, while the combination of an $(S)$-substrate and an $(R)$-ligand (or an $(R)$-substrate and an (S)-ligand) would be a matched pair in the cyclization.

Scheme 4. Cyclization of $(S)-\mathbf{1} \mathbf{j}$ with $\mathrm{Rh}^{+} /(R)$ - or $(S)-\mathrm{H}_{8}-\mathrm{BINAP}$.

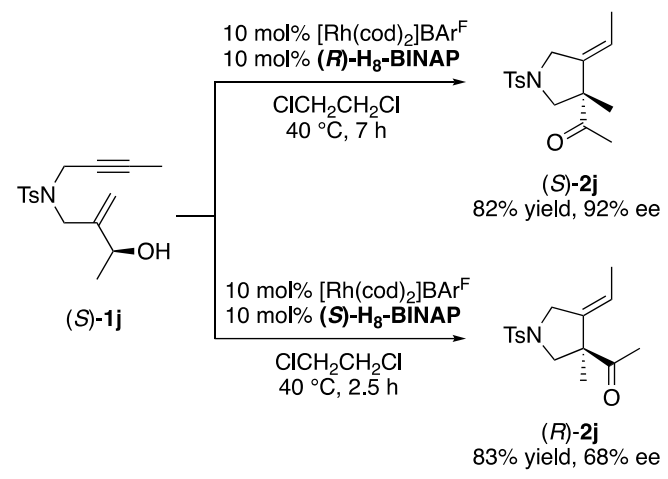

The different enantioselectivities in these cyclizations of a chiral substrate can be explained as follows (Scheme 5 ). In the cyclization of $(S)$-1 j using $(R)-\mathrm{H}_{8}$-BINAP (which is considered as a matched pair), the rhodacycle $\mathrm{i}$-a would be formed in preference to the rhodacycle i-b (eq. 5). ${ }^{[11]}$ Subsequently, $\sigma$-bond metathesis between the $\mathrm{Rh}-\mathrm{C}\left(\mathrm{sp}^{2}\right)$ bond and $\mathrm{O}-\mathrm{H}$ bond in the rhodacycle ii-a seems to occur without any interference to form the product $(S)$ 2j. On the other hand, $\sigma$-bond metathesis in the rhodacycle ii-b would be retarded due to the steric repulsion between the substituent $(\mathrm{R})$ and the pyrrolidine structure of ii-b, resulting in the product (S)-2 $\mathbf{j}$ instead of $(R)-\mathbf{2} \mathbf{j}$ being obtained through equilibration of rhodacycles $\mathbf{i}-\mathbf{a}, \mathbf{i}-\mathbf{b}, \mathbf{i}$ i-a, and $\mathbf{i i}-\mathbf{b} .{ }^{[13]}$ On the other hand, in the cyclization of $(S)-\mathbf{1} \mathbf{j}$ using $(S)-\mathrm{H}_{8}$-BINAP (i.e., a mismatched pair), the formation of the rhodacycle i-d should be preferred to that of the rhodacycle i-c (eq. 6). However, the steric repulsion between the substituent $(R)$ and the rhodacycle in ii-d would somewhat retard to form (S)-2e. As a result, in this case, the reaction would proceed through not only ii-d but also ii-c, resulting in a decrease in ee of the product.

In conclusion, we have developed a novel rhodium(I)catalyzed enantioselective intramolecular cyclization of enyne, having a hydroxy group in the tether, that affords various cyclic compounds with a chiral quaternary carbon center in high yields with high ees. The noteworthy point of this reaction is that the $\mathrm{Rh}$ $\mathrm{C}\left(\mathrm{sp}^{2}\right)$ bond in the rhodacyclopentene intermediate formed via enantioselective oxidative cycloaddition of enynes to a chiral rhodium(I) complex is intramolecularly cleaved by $\sigma$-bond metathesis of a tethered $\mathrm{O}-\mathrm{H}$ bond in the substrate. It is also noteworthy that various cyclic compounds, having a ketone moiety, were successfully obtained from racemic starting materials with high ees. Further studies along these lines are currently in progress.

Scheme 5. Possible reaction course. 


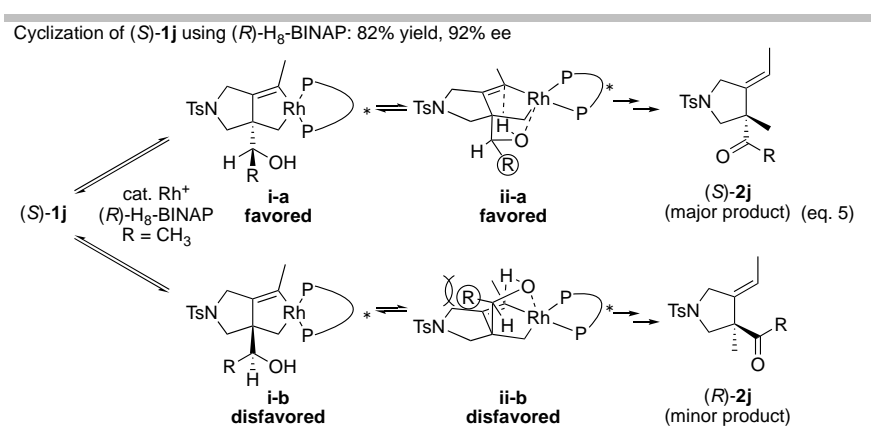

Cyclization of $(S)$-1j using (S)- $\mathrm{H}_{8}$-BINAP: $83 \%$ yield, $68 \%$ ee

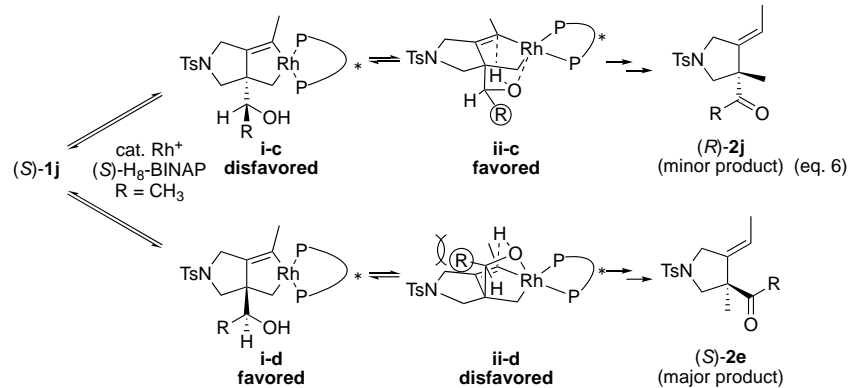

\section{Acknowledgements}

This work was financially supported by Grants-in-Aid for Scientific Research (B) (No. 26293001) and Grants-in-Aid for Scientific Research (C) (No. 17K08202) from JSPS. We thank Takasago International Corporation for the gift of $(R)$-BINAP, $(R)$-Tol-BINAP, $(R)$-Xyl-BINAP, and $(R)-\mathrm{H}_{8}$-BINAP.

Keywords: rhodium $\cdot$ cyclization $\cdot$ enyne $\cdot$ enantioselective $\bullet \sigma-$ bond metathesis

[1] For selected reviews, see: a) C. Aubert, O. Buisine, M. Malacria, Chem. Rev. 2002, 102, 813. b) V. Michelet, P. Y. Toullec, J.-P. Genêt, Angew. Chem. Int. Ed. 2008, 47, 4268; Angew. Chem. 2008, 120, 4338; c) A Marinetti, H. Jullien, A. Voituriez, Chem. Soc. Rev. 2012, 41, 4884.

[2] For selected examples of enantioselective Pauson-Khand reaction, see: a) K. Hiroi, T. Watanabe, R. Kawagishi, I. Abe, Tetrahedron Lett. 2000, 41, 891; b) K. Hiroi, T. Watanabe, R. Kawagishi, I. Abe, Tetrahedron: Asymmetry, 2000, 11, 797; For selected examples of enantioselective [2+2+2] cycloaddition, see: c) P. A. Evans, K. W. Lai, J. R. Sawyer, J. Am. Chem. Soc. 2005, 127, 12466; d) T. Shibata, Y. Arai, Y. Tahara, Org. Lett. 2005, 7, 4955; e) K. Masutomi, N. Sakiyama, K. Noguchi, K. Tanaka Angew. Chem. Int. Ed. 2012, 51, 13031; Angew. Chem. 2012, 124 13208; f) K. Masutomi, H. Sugiyama, H. Uekusa, Y. Shibata, K. Tanaka, Angew. Chem. Int. Ed. 2016, 55, 15373; Angew. Chem. 2016, 128 15599; g) H. Ueda, K. Masutomi, Y. Shibata, K. Tanaka, Org. Lett. 2017 19, 2913; h) K. Tanaka, Y. Otake, H. Sagae, K. Noguchi, M. Hirano, Angew. Chem. Int. Ed. 2008, 47, 1312; Angew. Chem. 2008, 120, 1332; i) M. Ishida, Y. Shibata, K. Noguchi, K. Tanaka, Chem. Eur. J. 2011, 17 12578.

[3] a) T. Shibata, Y. Tahara, J. Am. Chem. Soc. 2006, 128, 11766; b) T. Shibata, Y. Tahara, K. Tamura, K. Endo, J. Am. Chem. Soc. 2008, 130, 3451 .

[4] T. Suda, K. Noguchi, K. Tanaka, Angew. Chem. Int. Ed. 2011, 50, 4475; Angew. Chem. 2011, 123, 4567.

[5] K. Masutomi, K. Noguchi, K. Tanaka, J. Am. Chem. Soc. 2014, 136, 7627.

[6] For our recent studies on rhodium(I)-catalyzed cyclization of enyne, see: a) Y. Oonishi, Y. Hato Y. Sato, Adv. Synth. Catal. 2016, 358, 2273; b) Y. Hato, Y. Oonishi, Y. Yamamoto, K. Nakajima, Y. Sato, J. Org. Chem. 2016, 81, 7847.

[7] The geometry of alkene in 2a was determined by NOESY.
[8] When the reaction of 1a was carried out using $2.5 \mathrm{~mol} \%$ or $1 \mathrm{~mol} \%$ $\left[\mathrm{Rh}\left((R)-\mathrm{H}_{8}\right.\right.$-binap $\left.)\right] \mathrm{BAr} \mathrm{F}^{\mathrm{F}}$ under the same conditions except for the catalyst loading, 2 a was obtained in $74 \%$ yield with $93 \%$ ee $(24 \mathrm{~h})$ or in $31 \%$ yield with $95 \%$ ee $(90 \mathrm{~h})$.

[9] The ee of $\mathbf{2 g}$ and $\mathbf{2} \mathbf{i}$ was determined after reduction of the aldehyde moiety.

[10] The absolute configuration of $\mathbf{2} \mathbf{i}$ was assigned after chemical transformation (See Supporting Information for details.). The stereochemistry of cyclic compounds $\mathbf{2 a - 2 I}$ was assigned by analogy to $2 \mathbf{i}$.

[11] Tanaka reported that the formation of rhodacycle intermediate having a chiral carbon center at the ring-junction occurred by enantioselective oxidative cycloaddition of enynes bearing a 1,1-disubstituted alkene to an $\mathrm{Rh}^{+} /(R)-\mathrm{H}_{8}$-BINAP complex in rhodium(I)-catalyzed enantioselective $[2+2+2]$ cycloaddition. See ref. [2e]

[12] An alternative mechanism for the formation of $\mathbf{2}$ was also thought. Thus, the rhodium intermediate $\mathbf{v}$ was formed from $\mathbf{1}$, then 1,3-hydrogen shift of $\mathbf{v}$ occurred to give vi. Subsequently, the oxa- $\pi$-allyl rhodium intermediate vii was formed from vi, which was followed by carborhodation of vii and reductive elimination from viii to give the same product 2. At this stage, we cannot rule out either of the possibilities.
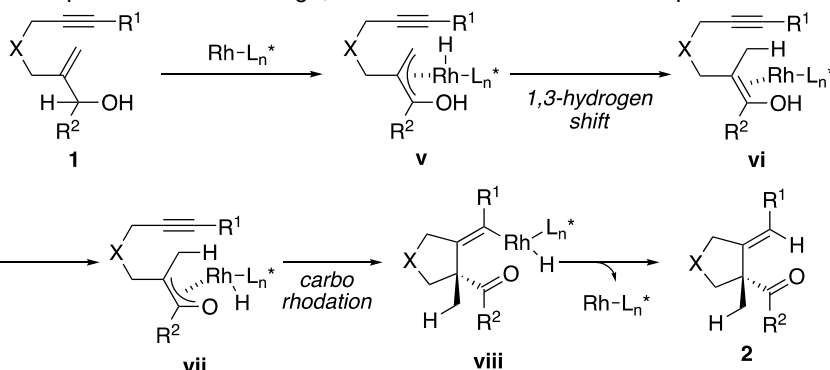

[13] It has been reported that the oxidative cycloaddition step of enyne with a rhodium complex is in equilibrium. See ref. [2e] 
Entry for the Table of Contents (Please choose one layout)

\section{COMMUNICATION}
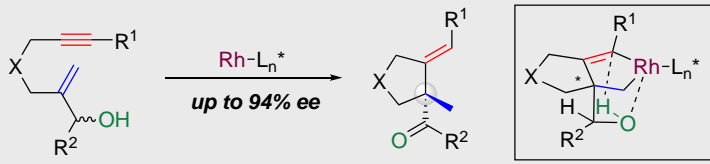

Rhodium(I)-catalyzed enantioselective intramolecular cyclization of enynes having a hydroxy group in the tether was investigated, and various cyclic compounds possessing a chiral quaternary carbon center were obtained in high yields with high ees. In this cyclization, an $\mathrm{Rh}-\mathrm{C}\left(\mathrm{sp}^{2}\right)$ bond in the rhodacyclopentene intermediate, which was formed via enantioselective oxidative cycloaddition of enynes to a chiral rhodium(l) complex, was intramolecularly cleaved by $\sigma$-bond metathesis of a tethered $\mathrm{O}-\mathrm{H}$ bond in the substrate. Furthermore, it was found that the cyclic compounds were obtained with high ees even when the starting materials having a racemic secondary alcohol moiety were used in this reaction.
Yoshihiro Oonishi*, Shuichi Masusaki, Shunki Sakamoto, and Yoshihiro Sato*

Page No. - Page No.

Rhodium(I)-Catalyzed

Enantioselective Cyclization of Enynes via Intramolecular Cleavage of the Rh-C Bond by a Tethered Hydroxy Group 